\title{
Sexual Harassment at Workplace: A Systematic Review of Literature
}

\author{
Tarikul Islam ${ }^{1}$, Tarik Raihan $^{2 *}, \&$ Md. Aftab Uddin ${ }^{3}$ \\ ${ }^{1}$ Graduate Student, Department of Human Resource Management, University of Chittagong, Chattogram, Bangladesh \\ ${ }^{2}$ Assistant Professor, Department of Management, University of Chittagong, Chattogram, Bangladesh \\ ${ }^{3}$ Associate Professor, Department of Human Resource Management, University of Chittagong, Chattogram, Bangladesh \\ ${ }^{*}$ Corresponding Author: tarikraihancu@gmail.com.
}

DOI: https://doi.org/10.38157/business-perspective-review.v2i2.128

Citation: Islam, T., Raihan, T. \& Uddin, M. A. (2020). Sexual Harassment at Workplace: A Systematic Review of Literature. Business Perspective Review 2(2), 1-14. DOI: https://doi.org/10.38157/business-perspective-review.v2i2.128

\section{Research Article}

\begin{abstract}
Purpose: Globally, sexual harassment is a burgeoning issue, which has been witnessed everywhere. Gripping the gravity of its significance, the present study sets forth to explore the reasons of sexual harassment in organizational settings.

Methods: Following the three-stage approach, a systematic review of the available literature was done extensively. A list of 3380 articles published from 2010 to 2019 were derived from widely explored databases, such as Taylor and Francis Online, Science Direct, JSTOR and Emerald Insight. 67 studies were selected from the list based on their relevance and suitability.

Results: From the extensive literature review, it is revealed that there are five dominant reasons for the widespread sexual harassment, namely 'inadequate governmental laws and organizational policies,' 'perceptions and attitudes,' 'male dominance', 'power differentials and organization structure' and 'cultural influence'.

Implications: To abate its further disastrous consequences, the present research proposes some intervention by linking the current observation with the previous empirical and theoretical studies. Directions for the future research are also provided.
\end{abstract}

Keywords: Sexual harassment, Workplace, Systematic Literature review

\section{Introduction}

Recently the workplace sexual harassment $(\mathrm{SH})$ has received voluminous attention among the academics, and professionals. The studies have documented that sexual harassment is prevailing not because of the victims' sexual disposition but because of other issues that are making the workplace unsafe for them. The studies revealed the magnitude and pervasiveness of the issue in today's workplace. A recent survey of Zillman (2017) documented that more than half of American women$54 \%$ - have experienced "inappropriate sexual moves" at some point in their career. Similarly, another survey, reported in 2015, observed that one in every three women, between the ages of 18-34, 
experienced sexual harassment (SH) at work in the US setting at some point in their career (Vagianos, 2015). The \#me too movement is only another recent hype to say and to understand how much pervasive $\mathrm{SH}$ is. $\mathrm{SH}$ is not only the case of the US. Instead it, seemingly, exists in the rests of the world. An attempt, a wide range of surveys among UK business organizations, reported more than half (52\%) of the women fell victim of inappropriate sexual drives by their counterparts at work (Brown, Gouseti, \& Fife-Schaw, 2018). In the USA, fifty-eight percent of women in science, engineering, and medicine have been reported being affected by sexual harassment (Ceppa et al., 2019). In a survey, Australian human rights commission (2012) exhibited that over one in every five (21\%) people, irrespective of their gender, experienced $\mathrm{SH}$ in the workplace in the last five years. Notably, the rate is quite high-(55\%) if woman is in the state of 'separated' status. In Asia, the frequencies of SH at every spheres of live are reportedly quite high. Chowdhry (2010) showed that some women officers in Indian army committed suicide during the last couple of years due to unwanted sexual attempts, which is too inhumane to accept. SH, in Bangladesh, in public places has become one of the severe problems especially in urban areas which are threatening gender security and justice (Nahar, Van Reeuwijk, \& Reis, 2013). Nearly eighty-three percent female in Bangladesh is somehow sexually assaulted at home or workplace by male (Ahmed et al., 2014). This evidence is reasonably enough to say that we have yet to walk a long way to reach the dreamt horizon (Koehlmoos, Uddin, Ashraf, \& Rashid, 2009).

It is not prudent to raise questions on the sizable studies for eliminating $\mathrm{SH}$ in the workplaces. However, the development of effective responses to address $\mathrm{SH}$ has been limited to conceptual and pragmatic issues (McDonald, Charlesworth, \& Graham, 2015). Till today, SH is usually hidden, and not viewed as a revealing problem and, more importantly, it had been somewhat overlooked over the past few decades (Hunt, Davidson, Fielden, \& Hoel, 2010; Malhotra \& Srivastava, 2016). Therefore, drawing on the understanding of the prior studies, it seems superfluous to express how much emphasis this landscape still needs to navigate toward the path of desired equity in the workplace.

This article reviews the current body of literature with an eye kept open to mirror on the reasons that result in continuous presence of sexual harassment in the workplaces. The paper builds upon the recent studies, which have been reviewed in a systematic manner. At the outset, it discusses critical reasons for sexual harassment in workplaces, which are followed by logical underpinning that elucidates the problem with possible solutions given in the relevant literature. Then, the paper includes policy implications and future research directions. This paper explores and significantly contributes to the existing literature in the following ways. Firstly, previous study in this field mostly prioritizes the female as the focus of sexual harassment. This paper accommodates the issue of $\mathrm{SH}$ in the workplace regardless of gender. Secondly this paper demonstrates a more generalized reflection since it encompasses four different scholarly databases to locate and address the fundamental reasons for $\mathrm{SH}$ in the workplace. Another significant contribution of this paper is that this paper aims to investigate this issue from a general point of view rather than specific sector or industry.

\section{Method}

This study employed the three-stage approach proposed by Tranfield, Denyer, and Smart (2003) that entails planning the review, conducting the review, and reporting and dissemination. The method of the systematic literature review was applied in this paper, which is applied in previous studies (Ozeren, 2014; Tarí, 2011; Thorpe, Holt, Macpherson, \& Pittaway, 2005). Based

2 Published by Research \& Innovation Initiative, 3112 Jarvis Ave, Warren, MI 48091, USA 
on available literature, subject matter of the study was pertained and confined mainly to explore the real reasons for $\mathrm{SH}$ in the workplace. Besides, the paper entails thorough discussion-every problem is followed by a discussion-that either clarifies the SH problem or directs how to deal with it. However, the article does not prescribe any specific solution(s). Because we believe that finding solutions to these pressing problems warrant more rigorous studies, and certainly, it is even essential to find those. To limit the range of the study, the paper considered advanced search in widely studied databases, such as Taylor and Francis Online, Science Direct, JSTOR and Emerald Insight. Based on the study of Fink (2010), inclusion and exclusion criteria are followed:

Table 1. Inclusion and exclusion criteria for publication from 2010-2019

\begin{tabular}{|ll|}
\hline \multicolumn{1}{|c|}{ Inclusion criteria } & \multicolumn{1}{c|}{ Type } \\
\hline Sexual harassment in titles, abstracts, topic or keywords & Content \\
\hline Published from 2010 to 2019 & Publication date \\
\hline Language (English) & Publication language \\
\hline JSTOR, Emerald, Science Direct, and Taylor and Francis. & Journal \\
\hline \multicolumn{1}{|c|}{ Exclusion criteria } & Type \\
\hline $\begin{array}{l}\text { Letters, editorial notes, duplication, book reviews, conference } \\
\text { proceedings and unpublished studies. }\end{array}$ & Research design \\
\hline
\end{tabular}

Primarily, the study considered available published scholarly works from 2010 to the year 2019. The current review went forward and ended up according to the stringent suggestions proposed by Tranfield et al. (2003). We advanced this study with process mentioned in the study of Moher, Liberati, Tetzlaff, Altman, and The (2009) which comprises of identification, screening, eligibility, and inclusion. The search was done on the basis of 'relevance first (identification)', and the more we climbed the number of the articles, the less we found them relevant. Therefore, we explored up to the scholarly works that we found relevant enough to consider. Among all databases, the initial screening was done based on title and appeared keywords of a paper. We went through a 'double-check' process to make sure that no literature is unchecked and all the scholarly works that seemed lacking specific focus were also considered the next screening.

For all the selected databases, thorough reading of abstracts functioned as the groundwork of the 2nd screening (screening) whereas the 3rd (eligibility) and final screening (inclusion) were executed by reckoning the complete papers. Level of relevance of an article was measured according to the degree of its focus on sexual harassment in the workplace. Articles that were excluded in various stages mainly focused, or at least tended to focus, on domestic violence, workplace bullying or campus violence. Besides, a minimal number of articles were found more diverse and focused on something else other than $\mathrm{SH}$ at works. Furthermore, the list of excluded articles and book chapters was augmented with those that were not published in English.

We have used the flowchart, as mentioned by Moher et al. (2009), reported the method used in this study: 


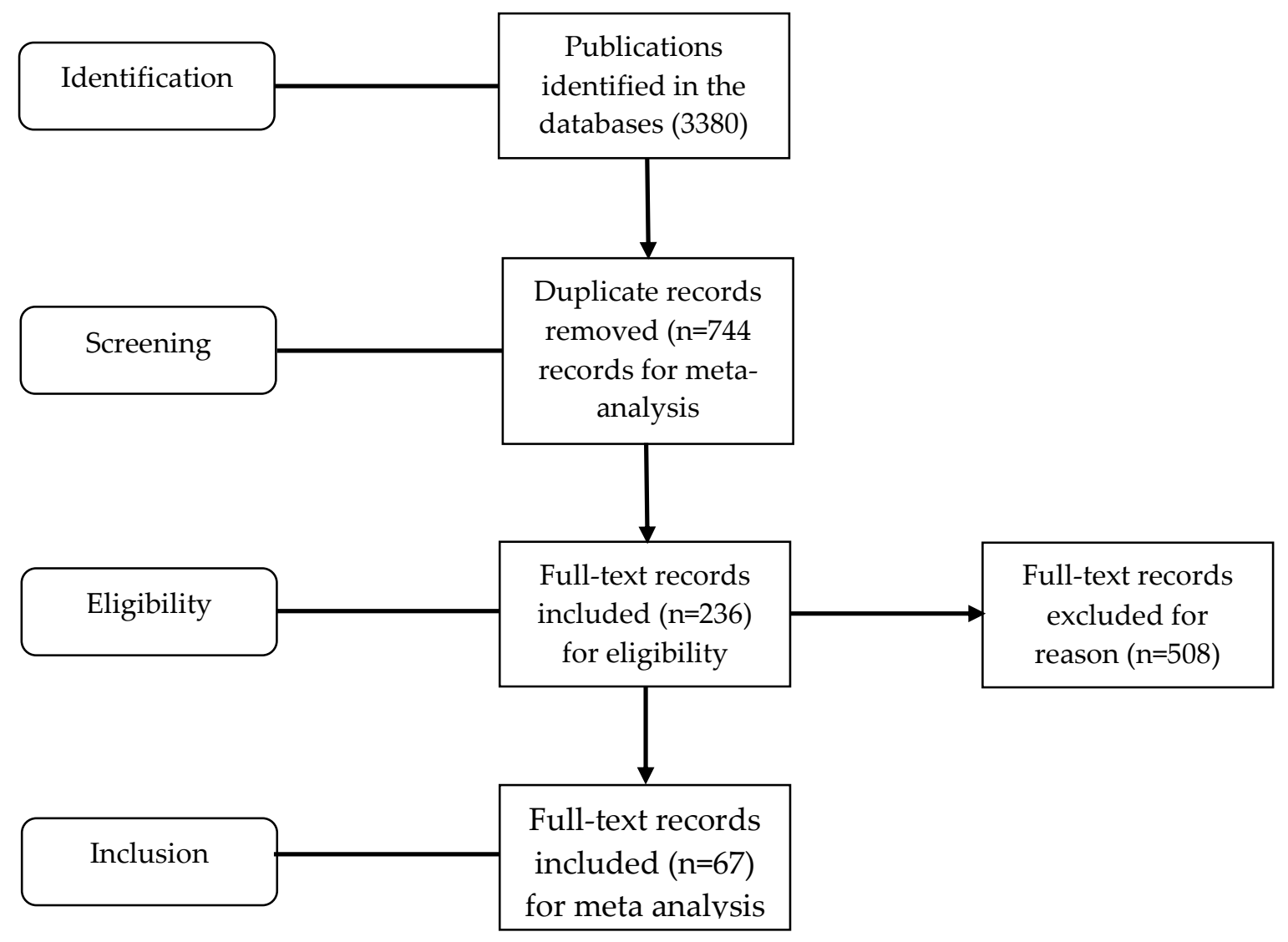

Fig. 1. Flow of information in systematic literature review

\section{Review outcome}

Finally, through a long and structured analysis, shown in figure 1, 3380 articles were reduced to 67 as only they were found serving the study's purpose. Despite incidences of sexual harassment are mushrooming over the past years, it is observed that the growth of studies is slowing down. Figure 2 demonstrates the trend of research over the past decade.

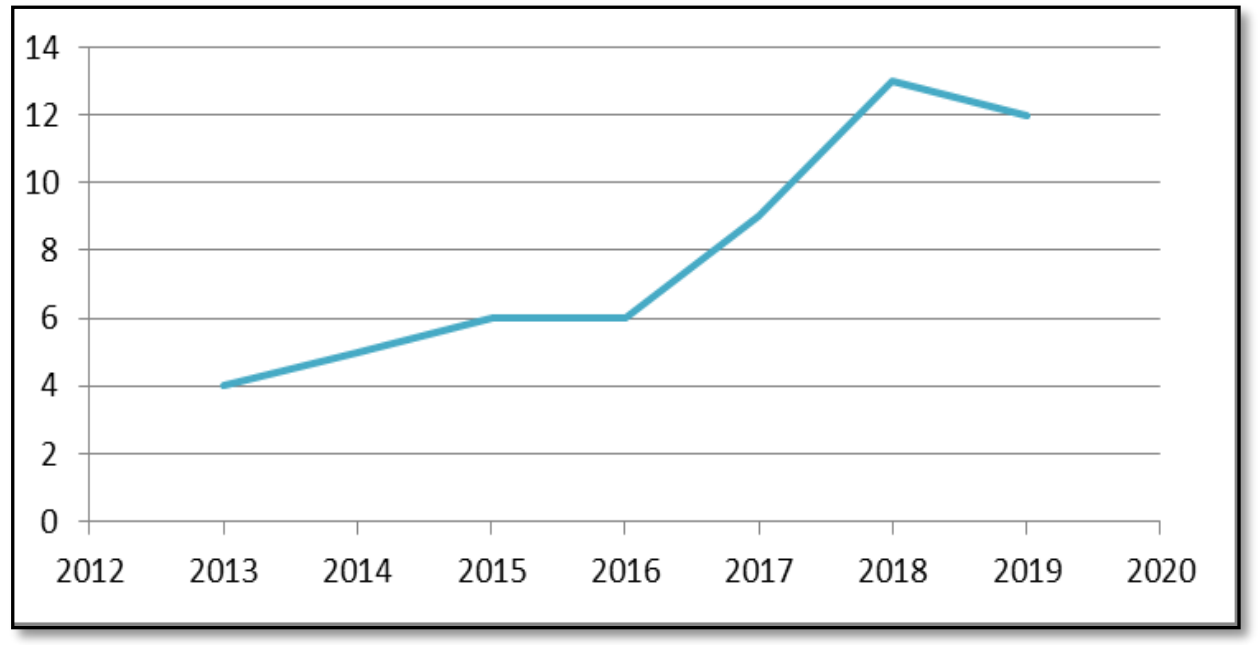

Fig. 2. Publication on sexual harassments over the past decade 
Among multiple reasons, five essential antecedents of sexual harassment were revealed, which were viewed as the substantial causes of forming $\mathrm{SH}$ in organizations. To the contrary, it is noteworthy to mention that many researchers primarily have focused on or ultimately have found specific problems or solutions that are not always identical to each other. Henceforth, the most revealing issues causing sexual harassment are described herewith.

\subsection{Laws and policies}

Absence of proper execution of governmental statutes and organizational policies can push $\mathrm{SH}$ to a horrified higher level whereas the presence of the former pulls it down to an optimum lower level. Extant literature coined that how complexity of legal system and regulatory mechanism, and overall deterioration of human society as well as poor implementation of governmental (both state and federal) laws and organizational policies result $\mathrm{SH}$ in the workplace. Additionally, the prevailing laws (special reference to India, Sri Lanka and Tanzania) are found inadequate to protect employees from SH in the workplaces (Alagappar \& Marican, 2014; Niriella, Dona, \& Shirajanie, 2015; Shakthi, 2019; Vuckovic, Altvater, Helgesson Sekei, \& Kloss, 2017). Even worse, in some cases laws are misused as well (Bhattacharya, 2014). In USA, ironically, rules have been engineered in such a way that men fail to see themselves as potential perpetrators or victims, and women recognize the disempowering effect of being associated with victim (Tinkler, 2012). While commenting on US laws, Findley, Dodd-Walker, Edwards, and Pappanastos (2014) contended that same-sex harassment is not only sophisticated but also confusing. Insufficiency and ineffectiveness of governmental laws, unnecessarily, continue to organizational policies and procedures that are often wrapped with ambiguity (Donnelly, Kerr, Heron, \& DiCarlo, 2016; Marshall, Dalyot, \& Galloway, 2014; Taber, 2017). Furthermore, laws and policies formulated by the government and organizations are misaligned, which eventually remains abstinent to prevent SH at workplace (Kmec, Hirsh, \& Skaggs, 2016; McLaughlin, Uggen, \& Blackstone, 2012).

However, responsible individuals and authorities are not just sitting idly but failing in one way or another. Laws and policies have evolved and changes are being made according to needs though we yet to observe their real consequences in the light of disappearing the $\mathrm{SH}$ (Bhattacharya, 2014; Price, 2013; Stanley \& Baldwin, 2011). Most policy suggestions and academic notes elicited to come up with some explicit interventions and applications of the same followed by adequate and effective laws and policies (Herovic, Scarduzio, \& Lueken, 2019; Hunt et al., 2010; Malhotra \& Srivastava, 2016) while many others recommend the importance of effective laws and policies at different levels to prevent SH (Fasting \& Sand, 2015; Nielsen et al., 2017; Tseng \& Kang, 2015).

\subsection{Attitude and perception}

Attitudes and perceptions of victims, perpetrators and the authorities of regulatory bodies have considerable roles and outcomes in SH cases. Restaurants and bars, for example, are perceived to be potential areas where sexual behavior are anticipated and mostly tolerated (Waudby \& Poulston, 2017). Ideally, this perception might not be destined to specified industries, like 
restaurants and bars. Women in Sri Lanka, China and Saudi Arabia who have been working in both public and private sectors have to endure sexual comments and demands by their superiors and co-workers as the price for economic survival (Bader, 2018; Niriella et al., 2015; Syed, 2018), that indicates a particular common perception. Study showed that women who complain SH incidences experience that the convicted (in their eyes) perpetrators usually remain unpunished (Chowdhry, 2010) and pretty often, complaints are not taken seriously (Adams, Darj, Wijewardene, \& Infanti, 2019; Foster \& Fullagar, 2018; Saberi, Motalebi Kashani, \& Dehdashti, 2019)- this attitudinal belief sets another common perception. Moreover, public sentiment, in general, are not strong enough to strengthen remedial actions against those delinquent behavior (Otenyo \& Camarillo, 2017). In consequences, the victims give up their hope and see themselves in repeated SH incidences, and the perpetrators go unpunished and get encouraged and have room to commit this crime again and again.

The reformation of perceptions as well as attitudes of victims and perpetrators toward SH must change through the revival of the laws and policies by the local authorities, governmental agencies, and business firms. However, as the question may arise, how to change the perceptions and attitudes of the responsible ones? Intimately, neither the governments around the world necessarily need to take pressure handling this social rampage, nor the business organizations require counting millions of dollars for the same. Reportedly, \#me too movement led to dramatic decline of many firms' stock prize (Hemel \& Lund, 2018). It is found that employees are aware of and impacted by high profile sexual assault cases (Rosenthal, Smith, \& Freyd, 2017). Besides, employees' intention to report SH cases depends on their perception of organizations anti-harassment policy and risks associated (Tseng \& Kang, 2015). In addition, employees hope to get support depends on organization's caring about fair and equal environment for (Hershcovis, Parker, \& Reich, 2010). It was also spitted-out that employees' perception of their organization's support of equal-opportunity initiatives mitigated the adverse effects of SH (Hershcovis et al., 2010). Therefore, overall, formation and implementation of effective laws and policies might be the right vaccine to deal with perceptions and attitudes associated with $\mathrm{SH}$.

\subsection{Male dominance}

The existing literature exhibits that the percentage of men, opposed to women, in different organizations is another pivotal reason to impact and incidences of SH. Male dominance (higher percentage of men) in various industries against fewer women makes the job prone to $\mathrm{SH}$ (Hershcovis et al., 2010; Kim, Vasquez, Torres, Nicola, \& Karr, 2016; Saunders \& Easteal Am, 2013). Moreover, female workers face acute workplace hostility male-dominated organizations (Lee, 2018; Nukala, Freedman-Weiss, Yoo, \& Smeds, 2019). As insufficient laws and policies along with perceptions and attitudes force women to a weaker position, it is reasonable to digest that dominance of men causing women to an even worse situation. However, it is noteworthy to highlight that men also are sexually violated by both male and female employees in various work settings (Hershcovis et al., 2010; Taber, 2017; Vuckovic et al., 2017) and sometimes women do it against women as well (Dyer et al., 2019; Findley et al., 2014). 
The solution, in general, is to keep the gender gaps in check/balance in workplace settings (Nemoto, 2010), and to empower women in the organizations (Otenyo \& Camarillo, 2017). Due to the glass ceiling affect women have significantly unequal representation in relatively higher management level where they are even more vulnerable to be sexually harassed (Mollah \& Uddin, 2018). Glass ceiling is defined as the invisible barrier that separates women and minorities from top management ladder at corporate boardroom (Robbins, Coulter, \& Vohra, 2011). However, it is noteworthy to state that SH does exist in countries with high level of gender equality and protected rights (Sorensen, 2018).

\subsection{Power differential in the organizational hierarchy}

Many authors attributed power difference as a reason for SH (Fasting \& Sand, 2015; Kim et al., 2016). Unequal power distribution and mismatches between persona and job in an organizational hierarchy contribute to escalating the power distance in any organization. Employees, sometimes, are required to meet sexual demands of superiors and peers to stay afloat and maintain their jobs (Kim et al., 2016; Kleppe \& Røyseng, 2016; Niriella et al., 2015; North, 2016). Often- for example at military work setting- power differential puts the victims in a position from where the victims can only accept their fate (Kovitz, 2018). Also, though SH is pervasive in different work settings, only a small number of victims report to higher authorities (Camargo, Liu, \& Yousem, 2017; Chowdhry, 2010; Herrera, Herrera, \& Expósito, 2014; Kleppe \& Røyseng, 2016; Syarifah \& Sharifah, 2015).

Therefore, power difference and organizational structure, individually or together, like perceptions and attitudes, may work as sources of SH at works. Usually, power difference originates from the organizational administrative structure. Thus, structural reformation and adjustment are needed to resolve the unequal power disposition to mitigate the $\mathrm{SH}$ issues at work. Power distribution across position based on skill and ability to perform a job rather than based on gender can improve the SH condition at workplace significantly (Niriella et al., 2015). Equality at work can also help the organization to recognize and solve the $\mathrm{SH}$ as form of employee discrimination (Marshall, 2015).

\subsection{Cultural influence}

Societal and cultural diversity plays a unique role in determining the attitude towards personal violence and sexual harassment in a society (Kivivuori, 2014). A dogmatic superstitious society smoothens the growth of rutted stance towards a particular gender, which upholds and establishes the masculine ideology. SH and gender discrimination also prevail in a society which is conducive to social stereotyping, as women are never be seen as equal as men and objectify as sexual symbols (Minkina, 2019). An organizational culture with high power differentials and improper legal framework provide more support to the harasser than the harassed (Keyton et al., 2018; Kleppe \& Røyseng, 2016). A regular footing to the sexual contact, male-ascendant workplace culture and powerlessness of female workers have been accused as the responsible factors for sexual harassment (Nemoto, 2010). The acceptability and apposite of different cognition and behavior are decided by values and norms constructed under an 
inevitable social reality (Yee, Alagappar, \& Ngeow, 2015). Internalization of conformational attitudes about women sometimes promotes an individual to accept sexual harassment myth (Ho, Dinh, Bellefontaine, \& Irving, 2018). Moreover collectivist culture imposes more blame and shame to the harassed than the individualistic culture because of inexperience and lack of recognition of fault (Ho et al., 2018; Rodríguez \& Gill, 2011), whereas conservatives are less concerned about sexual harassment than the liberals (van der Linden \& Panagopoulos, 2019).

To minimize these negative consequences, cultural apathy and inclusion, mutual trust, respect and recognition of personal contributions are the primary footstep towards the development and protracting less harassment culture. Authentic leadership is also necessary to bring proactive changes in social and cultural myth (Lee, 2018; Tseng \& Kang, 2015).Zero tolerance for sexual harassment, no harassment guideline for employees, sufficient employee development and awareness program, mutually respectful working climate, ethical practice and value-based management are essential to creating a workplace culture that dispirits the sexual harassment (Lee, 2018; von Gruenigen \& Karlan, 2018; Young \& Hegarty).

\section{Pervasiveness of sexual harassment}

SH has become simply unstoppable these days regardless of industry and work settings. It is no surprise that traditional work settings were investigated most in this regard (Hsu, Liu, \& Tsaur, 2019; VučetićAleksa, 2018) as in actual sense by workplace we mean the traditional work setting. However, interestingly, the military has received significant scholarly attention and almost invariable marked as a worst place for this serious problem (Averill et al., 2018; Barth et al., 2016; Kohlman; Taber, 2017). Academia (Gialopsos, 2017; Marshall et al., 2014; Rosenthal et al., 2017) sports organization (Fasting \& Sand, 2015; Johansson \& Lundqvist, 2017; Syarifah \& Sharifah, 2015), theatre (Kleppe \& Røyseng, 2016), and newspaper industry (North, 2016) are among the non-traditional work settings where $\mathrm{SH}$ found as pervasive.

\section{Implications for governments and organizations}

Responsible and corporate citizens must admit this pressing problem and try to adopt remedial measures to reduce its intensity if complete removal is not possible though. We strongly recommend that the intervention of $\mathrm{SH}$ should begin from the government through development and implementation of adequate and efficient laws that must be aligned with organizational policies and practices.

The organizations must ensure that they formulate effective policies and implement those effectively to deal with SH. Besides, they must confirm that every employee knows the policies and procedures thoroughly and does practice them whenever required. To establish an organization's perceptions and attitudes toward $\mathrm{SH}$, one easy step would be to inform all employees the organization's strong standing (we say zero tolerance) against SH through whistle blowing. Male dominance, another vital issue to consider, is relatively more in mid and higher managerial positions, which is dubbed as 'Big Boys Club', where women are usually not welcome. Organizations must look for some policy measures to remove the glass ceiling for 
women to ensure the beauty of diversity and bring a balance of power in terms of gender equity.

\section{Conclusion}

$\mathrm{SH}$ has long been a serious concern for the organizations regardless of size, industry, nature, and location. Also, scholars and policymakers around the world have been working on this pressing workplace issue. However, researchers failed to reap the benefits of the diligence as they were prevented to know the exact forces causing much-studied problem. The current study reveals inadequate governmental laws and organizational policies, perceptions and attitudes of perpetrators and victims, male dominance, power differentials and organizational structure, and cultural influence are the critical reasons for $\mathrm{SH}$ at works. Laws and policies that are formulated by the governments and the organizations themselves are found inadequate or limited. Attitude and perception of the victims, perpetrators, and the regulatory bodies are revealed as a noteworthy reason for prevailing $\mathrm{SH}$ at works. It is also found that women are particularly vulnerable to $\mathrm{SH}$ in the male-dominated workplaces. Besides, the review exposes that power differential in organizational hierarchy and societal and organizational culture have significant relationship with the $\mathrm{SH}$ instances. Finally it can be concluded with an observation that intervention of $\mathrm{SH}$ lies in formation and implementation of sufficient and effective governmental laws and organizational policies that must be aligned to each other.

\section{Limitations of the study}

Despite the underlying theoretical and managerial implications, the present study is not free from limitations demonstrating the signals for the future researchers. We had a selection bias of the published articles because we only collected records from JSTOR, Emerald, Science Direct, and Taylor and Francis databases. It is surely preventing the generalizability of the insights on the proposed narratives. A non-biased consideration by including entirely all databases could prevent this constraint. Beside we considered all the academic stock of knowledge, particularly articles, from 2010 to 2019 which displays our limited focus and prevents us to consider few dominant papers in our observed field. Thus, our study negates the significant contributions before 2010 if there was any. Moreover, the study did not consider on-going and unpublished works and, also, studies had to be published in English to be included in the review process. Findings might not remain the same and even could be contradictory, if the excluded sources were explored. Finally, this study elicited the factors influencing sexual harassment at workplace. However, no attempt has been made to unearth the impacts of sexual harassment at workplace. Thereby, its focus is very limited on identifying the reasons impacting sexual harassment.

\section{Research gaps and directions for future research}

No one can deny the presence of voluminous work regarding sources, output, and solutions of $\mathrm{SH}$, but still we are to find some pragmatic and appropriate solutions to SH. Hence, the initial misconception should be eradicated and need to have the belief that SH prevails everywhere 
and not yet sufficiently addressed. This systematic review reveals some critical reasons and possible solutions for $\mathrm{SH}$ along with some associated themes. However, to find out all and more exact causes and rigorous solutions, research should be conducted extensively- considering relatively larger literature body. A critical finding of the study is the absence of appropriate governmental laws and organizational policies to tackle SH. Therefore, research should be devoted to how to enact adequate laws that deals with SH efficiently and does not misalign with organizational policies and practices. Developed countries, like the USA, apparently have better laws and implementation, although yet to develop the perfect ones.

On the other hand, developing countries, such as Sri Lanka, Tanzania, India or Bangladesh, are comparatively lagging behind in formulation and implementation of required laws; which substantiates huge space and needs for conducting scholarly works. Another issue that the study concludes is that perceptions and attitudes of perpetrators and victims have significant impacts on the intensity of SH occurrences. Accordingly, they should be handled through proper laws and policies. The current body of literature surprisingly excludes the term 'zero tolerance'. Therefore, studies may provide specific focus on how to align 'zero tolerance' among governmental laws, organizational policies, and overall practices.

Acknowledgement: Authors are genuinely grateful to the authority of the 5th International Integrative Research Conference on Governance, and Modernization in Changing Environment for their insightful comments to improve this paper.

Author Contributions: Tarikul Islam and Md. Aftab Uddin conceptualized the idea, Tarikul Islam and Tarik Raihan collected data, three authors contributed equally in writing of this paper

Conflicts of Interest: We certify that all the authors have approved the paper for the release and are in agreement with its content.

\section{REFERENCES}

Averill, L., Smith, N. B., Holens, P. L., Sippel, L. M., Bellmore, A. R., Mota, N. P., Pietrzak, R. H. (2018). Sex Differences in Correlates of Risk and Resilience Associated with Military Sexual Trauma. Journal of Aggression, Maltreatment \& Trauma, 1-17.

Adams, E. A., Darj, E., Wijewardene, K., \&Infanti, J. J. (2019). Perceptions on the sexual harassment of female nurses in a state hospital in Sri Lanka: a qualitative study. Global Health Action, 12(1), 1560587. doi:https://doi.org/10.1080/16549716.2018.1560587

Ahmed, S. I., Jackson, S. J., Ahmed, N., Ferdous, H. S., Rifat, M. R., Rizvi, A. S. M., . Mansur, R. S. (2014). Protibadi. 2695-2704. doi:10.1145/2556288.2557376

Alagappar, P. N., \&Marican, S. (2014). The issue of sexual harassment legislation in a mainstream newspaper in Malaysia. Procedia - Social and Behavioral Sciences, 155, 368-373. doi:https://doi.org/10.1016/j.sbspro.2014.10.307

Bader, B. (2018). Institutional discrimination of women and workplace harassment of female expatriates. Journal of Global Mobility, 6(1), 40-58. doi: https://doi.org/10.1108/JGM-06-2017-0022

Barth, S. K., Kimerling, R. E., Pavao, J., McCutcheon, S. J., Batten, S. V., Dursa, E., . . Schneiderman, A. I. (2016). Military sexual trauma among recent veterans: Correlates of sexual assault and sexual harassment. American Journal of Preventive Medicine, 50(1), 77-86. doi: https://doi.org/10.1016/j.amepre.2015.06.012 
Bhattacharya, M. (2014). Can law help women to survive? Social Scientist, 42(1/2), 3-12.

Botha, D. (2016). Women in mining: An assessment of workplace relations struggles. Journal of Social Sciences, 46(3), 251-263. doi:https://doi.org/10.1080/09718923.2016.11893533

Brown, J., Gouseti, I., \& Fife-Schaw, C. (2018). Sexual harassment experienced by police staff serving in England, Wales and Scotland: A descriptive exploration of incidence, antecedents and harm. The Police Journal: Theory, Practice and Principles, 91(4), 356-374. doi: https://doi.org/10.1177/0032258x17750325

Camargo, A., Liu, L., \&Yousem, D. M. (2017). Sexual Harassment in Radiology. Journal of the American College of Radiology, 14(8), 1094-1099. doi:https://doi.org/10.1016/j.jacr.2017.02.054

Ceppa, D. P., Dolejs, S. C., Boden, N., Phelan, S., Yost, K. J., Donington, J., Blackmon, S. (2019). Sexual Harassment \& Cardiothoracic Surgery-\#UsToo? The Annals of Thoracic Surgery. doi:https://doi.org/10.1016/j.athoracsur.2019.07.009

Chowdhry, P. (2010). Women in the Army (Vol. 45).

Donnelly, P., Kerr, G., Heron, A., \& DiCarlo, D. (2016). Protecting youth in sport: an examination of harassment policies. International Journal of Sport Policy and Politics, 8(1), 33-50. doi:https://doi.org/10.1080/19406940.2014.958180

Dyer, K. E., Potter, S. J., Hamilton, A. B., Luger, T. M., Bergman, A. A., Yano, E. M., \&Klap, R. (2019). Gender differences in veterans' perceptions of harassment on veterans health administration grounds. Women's Health Issues, 29, S83-S93. doi: https://doi.org/10.1016/j.whi.2019.04.016

Fasting, K., \& Sand, T. S. (2015). Narratives of sexual harassment experiences in sport. Qualitative Research in Sport, Exercise and Health, 7(5), 573-588. doi: https://doi.org/10.1080/2159676X.2015.1008028

Findley, H., Dodd-Walker, E., Edwards, J., \& Pappanastos, E. (2014). Same-sex harassment: how hostile does it have to be? International Journal of Law and Management, 56(5), 417-428. doi: https://doi.org/10.1108/IJLMA-082013-0038

Fink, A. (2010). Conducting Research Literature Reviews: From the Internet to Paper. CA: Sage Publications.

Foster, P. J., \&Fullagar, C. J. (2018). Why don't we report sexual harassment? An application of the Theory of Planned Behavior. Basic and Applied Social Psychology, 40(3), 148-160. doi:https://doi.org/10.1080/01973533.2018.1449747

Gialopsos, B. M. (2017). Sexual Violence in Academia: Policy, Theory, and Prevention Considerations. Journal of School Violence, 16(2), 141-147. doi: https://doi.org/10.1080/15388220.2017.1284467

Hemel, D., \& Lund, D. S. (2018). Sexual harassment and corporate law. Columbia Law Review, 118(6), 1583-1680.

Herovic, E., Scarduzio, J. A., \& Lueken, S. (2019). "It literally happens every day": The multiple settings, multilevel considerations, and uncertainty management of modern-day sexual harassment. Western Journal of Communication, 83(1), 39-57. doi: https://doi.org/10.1080/10570314.2018.1485052

Herrera, M. C., Herrera, A., \& Expósito, F. (2014). Stop Harassment! Men's reactions to victims' confrontation. European Journal of Psychology Applied to Legal Context, 6(2), 45-52.

Hershcovis, M. S., Parker, S. K., \& Reich, T. C. (2010). The moderating effect of equal opportunity support and confidence in grievance procedures on sexual harassment from different perpetrators. Journal of Business Ethics, 92(3), 415-432. doi:https://doi.org/10.1007/s10551-009-0165-2

Ho, I. K., Dinh, K. T., Bellefontaine, S. M., \& Irving, A. L. (2018). Cultural adaptation and sexual harassment in the lives of asianamerican women. Women \& Therapy, 41(3-4), 281-297. doi: https://doi.org/10.1080/02703149.2018.1430300

Hsu, F.-S., Liu, Y.-a., \&Tsaur, S.-H. (2019). The impact of workplace bullying on hotel employees' well-being. International Journal of Contemporary Hospitality Management, 31(4), 1702-1719. doi:https://doi.org/10.1108/IJCHM-04-2018-0330

Hunt, C. M., Davidson, M. J., Fielden, S. L., \&Hoel, H. (2010). Reviewing sexual harassment in the workplace - an intervention model. Personnel Review, 39(5), 655-673. doi: https://doi.org/10.1108/00483481011064190

Johansson, S., \& Lundqvist, C. (2017). Sexual harassment and abuse in coach-athlete relationships in Sweden. European Journal for Sport and Society, 14(2), 117-137. doi: https://doi.org/10.1080/16138171.2017.1318106

Keyton, J., Clair, R., Compton, C. A., Dougherty, D. S., Forbes Berthoud, D., Manning, J., \&Scarduzio, J. A. (2018). Addressing sexual harassment in a sexually charged national culture: a Journal of Applied Communication

11 Published by Research \& Innovation Initiative, 3112 Jarvis Ave, Warren, MI 48091, USA 
Research forum. Journal of Applied Communication Research, 46(6), 665-683. doi:https://doi.org/10.1080/00909882.2018.1546472

Kim, N. J., Vasquez, V. B., Torres, E., Nicola, R. M., \& Karr, C. (2016). Breaking the silence: Sexual harassment of mexican women farm workers. J Agro medicine, 21(2), 154-162. doi:https://doi.org/10.1080/1059924x.2016.1143903

Kivivuori, J. (2014). Understanding trends in personal violence: Does cultural sensitivity matter? Crime and Justice, 43(1), 289-340. doi:https://doi.org/10.1086/677664

Kleppe, B., \&Røyseng, S. (2016). Sexual harassment in the norwegian theatre world. The Journal of Arts Management, Law, and Society, 46(5), 282-296. doi: https://doi.org/10.1080/10632921.2016.1231645

Kmec, J. A., Hirsh, C. E., \& Skaggs, S. (2016). Workplace regulation of sexual harassment and federal and state-level legal environments Research in the Sociology of Work (pp. 215-240).

Koehlmoos, T. P., Uddin, M. J., Ashraf, A., \& Rashid, M. (2009). Homeless in Dhaka: violence, sexual harassment, and drug-abuse. Journal of Health, Population, and Nutrition, 27(4), 452-461.

Kohlman, M. H. Race, rank and gender: the determinants of sexual harassment for men and women in the military Interactions and Intersections of Gendered Bodies at Work, at Home, and at Play (pp. 65-94).

Kovitz, M. (2018). Sexual (mis) conduct in the Canadian forces. Critical Military Studies, 1-21. doi:https://doi.org/10.1080/23337486.2018.1494883

Lee, J. (2018). Passive leadership and sexual harassment. Personnel Review, 47(3), 594-612. doi:https://doi.org/10.1108/PR-07-2016-0169

Malhotra, S., \& Srivastava, A. (2016). Sexual harassment at the workplace: how organizations can pro-actively reduce its incidence. Human Resource Management International Digest, 24(7), 1-3. doi:https://doi.org/10.1108/HRMID-05-2016-0072

Marshall, A.M. (2015). Sexual Harassment: United States and Beyond. In V. Schultz (Ed.), International Encyclopedia of the Social \& Behavioral Sciences (Vol. 21, pp. 721-727): Elsevier.

Marshall, C., Dalyot, K., \& Galloway, S. (2014). Sexual harassment in higher education: Re-framing the puzzle of its persistence. Journal of Policy Practice, 13(4), 276-299. doi: https://doi.org/10.1080/15588742.2014.929070

McDonald, P., Charlesworth, S., \& Graham, T. (2015). Developing a framework of effective prevention and response strategies in workplace sexual harassment. Asia Pacific Journal of Human Resources, 53(1), 41-58. doi:https://doi.org/10.1111/1744-7941.12046

McLaughlin, H., Uggen, C., \& Blackstone, A. (2012). Sexual harassment, workplace authority, and the paradox of power. American Sociological Review, 77(4), 625-647. Doi :https://doi.org/10.1177/0003122412451728

Minkina, N. (2019). Can\# MeToo abolish sexual harassment and discrimination in medicine? The Lancet, 394(10196), 383-384.

Moher, D., Liberati, A., Tetzlaff, J., Altman, D. G., \& The, P. G. (2009). Preferred reporting items for systematic reviews and meta-analyses: The PRISMA statement. PLoS Medicine, 6(7), e1000097. doi:https://doi.org/10.1371/journal.pmed.1000097

Mollah, M. R. A., \& Uddin, M. A. (2018). Factors preventing women to climb up corporate echelon in banking sector: An empirical study of glass ceiling effect. BUP Journal, 6(Special), 69-83.

Nahar, P., Van Reeuwijk, M., \& Reis, R. (2013). Contextualizing sexual harassment of adolescent girls in Bangladesh. Reproductive health matters, 21(41), 78-86.

Nemoto, K. (2010). Sexual harassment and gendered organizational culture in Japanese firms Gender and Sexuality in the Workplace (pp. 203-225).

Nielsen, M. W., Alegria, S., Börjeson, L., Etzkowitz, H., Falk-Krzesinski, H. J., Joshi, A., . . Schiebinger, L. (2017). Opinion: Gender diversity leads to better science. Proceedings of the National Academy of Sciences, 114(8), 1740-1742. doi:https://doi.org/10.1073/pnas.1700616114

Niriella, M., Dona, A., \&Shirajanie, S. J. (2015). Sexual harassment against women in the workplace: A critical study on the regulatory framework in Sri Lanka Enabling Gender Equality: Future Generations of the Global World (pp. 41-55).

North, L. (2016). Damaging and daunting: female journalists' experiences of sexual harassment in the newsroom. Feminist Media Studies, 16(3), 495-510. doi: https://doi.org/10.1080/14680777.2015.1105275 
Nukala, M., Freedman-Weiss, M., Yoo, P., \&Smeds, M. R. (2019). Sexual harassment in vascular surgery training programs. Annals of Vascular Surgery. doi: https://doi.org/10.1016/j.avsg.2019.05.011

Otenyo, E. E., \& Camarillo, E. A. S. (2017). Mayors' and citizen attitudes toward sexual harassment in police departments Corruption, Accountability and Discretion (pp. 143-161).

Ozeren, E. (2014). Sexual orientation discrimination in the workplace: A systematic review of literature. Procedia Social and Behavioral Sciences, 109, 1203-1215. doi: https://doi.org/10.1016/j.sbspro.2013.12.613

Price, T. R. (2013). You've come a long way, baby: Stripping pornography from america's workplace: Robinson v. Jacksonville shipyards, inc., 760 f. Supp. 1486 (m.D. Fla. 1991). The Florida Historical Quarterly, 92(2), 261275.

Robbins, S. P., Coulter, M., \& Vohra, N. (2011). Management. New Delhi, India: Pearson Education.

Rodríguez, E. A., \& Gill, D. L. (2011). Sexual harassment perceptions among Puerto Rican female former athletes. International Journal of Sport and Exercise Psychology, 9(4), 323-337. doi:https://doi.org/10.1080/1612197X.2011.623461

Rosenthal, M., Smith, C. P., \&Freyd, J. J. (2017). Behind closed doors: university employees as stakeholders in campus sexual violence. Journal of Aggression, Conflict and Peace Research, 9(4), 290-304. doi:https://doi.org/10.1108/JACPR-02-2017-0272

Saberi, H. R., MotalebiKashani, M., \&Dehdashti, A. (2019). Occupational violence among female workers in an Iranian industrial area. Women \& Health, 1-13. doi: https://doi.org/10.1080/03630242.2019.1593285

Saunders, S., \&Easteal Am, P. (2013). The nature, pervasiveness and manifestations of sexual harassment in rural Australia: Does 'masculinity' of workplace make a difference? Women's Studies International Forum, 40, 121-131. doi:https://doi.org/10.1016/j.wsif.2013.05.013

Shakthi, S. (2019). The law, the market, the gendered subject: workplace sexual harassment in Chennai's information technology industry. Gender, Place \& Culture, 1-18. doi:https://doi.org/10.1080/0966369X.2019.1608912

Sorensen, I. (2018). What sexual harassment in Zentropa tells us about cultural policy post-Weinstein. Feminist Media Studies, 18(3), 502-505. doi:https://doi.org/10.1080/14680777.2018.1456165

Stanley, C. W., \& Baldwin, J. N. (2011). Sexual harassment in the accounting profession: Has the situation improved? Research on Professional Responsibility and Ethics in Accounting (pp. 75-99).

Syarifah, F. S. S., \& Sharifah, S. S. S. (2015). The occurrence of sexual harassment among sports practitioners in Bukit Jalil, Kuala Lumpur. Procedia - Social and Behavioral Sciences, 211, 917-923. doi:https://doi.org/10.1016/j.sbspro.2015.11.121

Syed, J. (2018). Gender equality in employment in Saudi Arabia: a relational perspective. Career Development International, 23(2), 163-177. doi: https://doi.org/10.1108/CDI-07-2017-0126

Taber, N. (2017). The Canadian armed forces: Battling between operation honour and operation hop on her. Critical Military Studies, 1-22. doi: https://doi.org/10.1080/23337486.2017.1411117

Tarí, J. J. (2011). Research into quality management and social responsibility. Journal of Business Ethics, 102(4), 623638. doi:https://doi.org/10.1007/s10551-011-0833-x

Thorpe, R., Holt, R., Macpherson, A., \& Pittaway, L. (2005). Using knowledge within small and medium-sized firms: A systematic review of the evidence. International Journal of Management Reviews, 7(4), 257-281. doi:https://doi.org/10.1111/j.1468-2370.2005.00116.x

Tinkler, J. E. (2012). Resisting the enforcement of sexual harassment law. Law \& Social Inquiry, 37(1), 1-24. doi:https://doi.org/10.1111/j.1747-4469.2011.01279.x

Tranfield, D., Denyer, D., \& Smart, P. (2003). Towards a methodology for developing evidence-informed management knowledge by means of systematic review. British Journal of Management, 14(3), 207-222. doi:https://doi.org/10.1111/1467-8551.00375

Tseng, L.-M., \& Kang, Y.-M. (2015). Anti-harassment policy, manager integrity and intention to report customer sexual harassment: A Taiwanese case study. Leadership \& Organization Development Journal, 36(5), 570 591. doi:https://doi.org/10.1108/LODJ-12-2013-0157

Vagianos, A. (2015). 1 In 3 Women Has Been Sexually Harassed At Work, According To Survey. Huffington Post. van der Linden, S., \& Panagopoulos, C. (2019). The O'Reilly factor: An ideological bias in judgments about sexual 


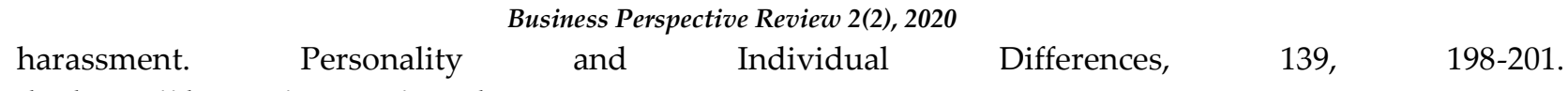
doi:https://doi.org/10.1016/j.paid.2018.11.022

von Gruenigen, V. E., \&Karlan, B. Y. (2018). Sexual harassment in the work place: Its impact on gynecologic oncology and women's health. Gynecologic Oncology, 149(2), 227-229. doi:https://doi.org/10.1016/j.ygyno.2018.02.018

VučetićAleksa, Š. (2018). Influence of specialized hotels on employees' perception of abuse in the selective tourism destination. International Journal of Contemporary Hospitality Management, 30(2), 740-756. doi:https://doi.org/10.1108/IJCHM-08-2016-0434

Vuckovic, M., Altvater, A., HelgessonSekei, L., \& Kloss, K. (2017). Sexual harassment and gender-based violence in Tanzania's public service: A study among employees in Mtwara Region and Dar es Salaam. International Journal of Workplace Health Management, 10(2), 116-133. doi: https://doi.org/10.1108/IJWHM-02-2015-0011

Waudby, B., \&Poulston, J. (2017). Sexualisation and harassment in hospitality workplaces: who is responsible? International Journal of Culture, Tourism and Hospitality Research, 11(4), 483-499. doi:https://doi.org/10.1108/IJCTHR-10-2016-0102

Yee, M. T. W., Alagappar, P. N., \&Ngeow, Y. M. (2015). Differences in the perception of sexual harassment by gender and ethnicity among selected Malaysian undergraduates. Gender, Technology and Development, 19(2), 204-230. doi:https://doi.org/10.1177/0971852415578042

Young, J. L., \& Hegarty, P. Reasonable men: Sexual harassment and norms of conduct in social psychology. Feminism \& Psychology, 0(0), 0959353519855746. doi: https://doi.org/10.1177/0959353519855746

Zillman, C. (2017). A new poll on sexual harassment suggests why 'me too' went so insanely viral fortune.Com. Retrieved from http://fortune.com/2017/10/17/me-too-hashtag-sexual-harassment-at-work-stats/ Attribution (CC BY) license (http://creativecommons.org/licenses/by/4.0/). 